\title{
¿ุCatalysis
}

\author{
Supporting Information
}

\section{Impactful Role of Cocatalysts on Molecular Electrocatalytic Hydrogen Production}

Charles G. Margarit, ${ }^{1}$ Naomi G. Asimow, ${ }^{1}$ Agnes E. Thorarinsdottir, ${ }^{1}$ Cyrille Costentin $^{2,3, *}$ and Daniel G. Nocera ${ }^{1, *}$

${ }^{1}$ Department of Chemistry and Chemical Biology, Harvard University, 12 Oxford Street, Cambridge, MA 02138, United States. ${ }^{2}$ Université de Paris, 75013 Paris, France. ${ }^{3}$ Département de Chimie Moléculaire, Université Grenoble-Alpes, CNRS, UMR 5250, 38000 Grenoble, France

*Corresponding author emails: cyrille.costentin@univ-grenoble-alpes.fr, dnocera@fas.harvard.edu 


\section{Table of Contents}

A. Experimental Details 3

A.1 General Considerations $\quad 3$

A.2 General Electrochemical Procedures 3

A.3 Product Quantification $\quad 4$

B. Electrochemical Experiments 5

B.1 AcOH Background CV 5

Figure S1. CV of solvent background and with added $\mathrm{AcOH}$

B.2 Simulation of TPPFe CVs in the Presence of ${ }^{+} \mathrm{HNEt}_{3}$

Figure S2. CV of TPPFe with varying ${ }^{+} \mathrm{HNEt}_{3} \quad 6$

Scheme S1. Reaction scheme for the reduction of TPPFe(II) and its reactivity with ${ }^{+} \mathrm{HNEt}_{3} \quad 6$

B.3 LSV with Water Titration $\quad 7$

Figure S3. LSV scans of TPPFe with $\mathrm{AcOH}$ and $\mathrm{N}\left(i-\mathrm{Pr}_{2}\right)$ Et with water titration 7

B.4 Determination of Association of Base to TPPFe $\quad 7$

Figure S4. CV of TPPFe in presence of amines 7

Figure S5. Plot of the TPPFe apparent standard potential with Quin and DABCO 8

B.5 Simulations of LSV to Obtain $k_{1, \text { ap }}$ and $k_{2, \text { ap }} \quad 8$

Scheme S2. Reaction scheme for the reduction of TPPFe(II) and its reactivity with $\mathrm{AcOH} \quad 8$

Figure S6. Apparent rate constant plots vs amine concentration 10

Figure S7. LSV and plots of $k_{1, \text { ap }}$ and $k_{2, \text { ap }}$ of TPPFe with AcOH and P(OMe $)_{3}$

B.6 Simulations of LSV to Obtain $k_{1, \mathrm{BH}^{+}}$and $k_{2, \mathrm{BH}^{+}}$

Scheme S3. Reaction scheme for the reduction of protons to $\mathrm{H}_{2}$ by TPPFe with amine 11

Table S1. Tabulated values for the conjugate acid $\mathrm{p} K_{a, B}$ and rate constants 12

Figure S8. Experimental and simulated LSVs of TPPFe with AcOH and amines 13

Figure S9. Adjustment of $k_{1, \text { ap }}$ and $k_{2, \text { ap }}$ with heteroconjugation of acid 14

Figure S10. $k_{2, \text { ap }}$ as function of added $\mathrm{P}(\mathrm{OMe})_{3}$ and fit to simulation 15

C. NMR Titration Experiments 16

Figure S11. NMR spectra of $\mathrm{AcOH}$ in presence of amines 16

D. IR Experiment 17

Figure S12. Infrared spectrum of $\mathrm{AcOH}$ and Quin $\quad 17$

$\begin{array}{lr}\text { E. References } & 18\end{array}$ 


\section{A. Experimental Details}

\section{A.1 General Considerations}

Acetic acid, tetraethylammonium acetate tetrahydrate, triethylamine hydrochloride, triethylamine, Nethylpiperidine, $\mathrm{N}, \mathrm{N}$-diisopropylethylamine, trimethylphosphite and [FeTPP]Cl were purchased from Sigma Aldrich and used as received. Diazabicyclooctane and quinuclidine were purchased from Alfa Aesar and used as received.

$\mathrm{N}, \mathrm{N}$-dimethylformamide (DMF) was purchased from Sigma Aldrich and purified by passage through alumina and stored over activated $3 \AA$ sieves under a nitrogen atmosphere for at least $24 \mathrm{~h}$ before use. Tetrabutylammonium hexafluorophosphate was purchased from Sigma Aldrich and was recrystallized from ethanol twice before being dried in vacuo at $70^{\circ} \mathrm{C}$ and stored under nitrogen atmosphere inside a glovebox.

${ }^{1} \mathrm{H}$ NMR spectra were recorded at ambient temperature on JEOL ECZ400S and Bruker AVANCE NEO 400B $400 \mathrm{MHz}$ spectrometers. All spectra were taken in DMF- $\mathrm{d}_{7}$, purchased from Cambridge Isotopes Laboratories and used as received, and referenced to aldehyde proton of residual DMF solvent (8.03 ppm $-{ }^{1} \mathrm{H}$ ). Measured values for $\delta$ are given in parts per million (ppm).

IR spectra were recorded in attenuated total reflection (ATR) mode on a Perkin Elmer 400 FT-IR spectrometer equipped with PIKE Technologies GladiATR accessory for ATR measurements. Samples for measurements were either glacial acetic acid (as recieved from Sigma Aldrich) or a mixture of glacial acetic acid and quinuclidine in 4:1 molar ratios.

\section{A.2 General Electrochemical Procedures}

All CV and bulk electrolysis experiments were conducted using a CH Instruments $760 \mathrm{C}$ potentiostat. CV measurements were carried out in an oven-dried custom glass cell (James Glass) using a 3.0 mm glassycarbon-dot working electrode (CH Instruments), platinum mesh counter electrode (BASi), and saturated calomel reference electrode ( $\mathrm{CH}$ Instruments) or Warner brand Leak-Free reference electrode. Working solutions comprised $3.0 \mathrm{~mL}$ of electrolyte solution containing $\mathrm{DMF}$ with $0.1 \mathrm{M} n-\mathrm{NBu}_{4} \mathrm{PF}_{6}, 1 \mathrm{mM} F$ porphyrin (TPPFe), and varying concentrations of amine, which was added as a $1 \mathrm{M}$ solution of amine in electrolyte solution. The calomel reference electrode was separated from the working solution by a double liquid junction salt-bridge (Hach) containing $8.0 \mathrm{~mL}$ of electrolyte solution and the Warner brand reference electrode was placed directly into the working solution. Working solutions were degassed with argon and kept under a positive pressure at all times. All experiments were referenced to the ferrocenium/ferrocene 
couple $\left(\mathrm{Fc}^{+} / \mathrm{Fc}\right.$ ) by dissolution of $\sim 1.0 \mathrm{mg}$ of ferrocene into the working solution and performing an anodic CV to obtain the reference potential. The working electrode was polished (Allied High Tech) after every CV with $3 \mu \mathrm{m}$ and $1 \mu \mathrm{m}$ diamond paste in ethanol (Struers), then rinsed, sonicated in ethanol to remove particulates, and rinsed with acetone before being dried under a nitrogen stream.

Bulk electrolyses were performed in a cylindrical glass cell fitted with a Hach salt bridge containing the counter solution and adapted for the continuous flow detection of gases. During flow experiments the working compartment contained $6.0 \mathrm{~mL}$ of DMF- $\mathrm{d}_{7}$ containing $0.1 \mathrm{M} n-\mathrm{NBu}_{4} \mathrm{PF}_{6}$ with $250 \mu \mathrm{M}$ TPPFe, $40 \mathrm{mM}$ of $\mathrm{AcOH}$, and $40 \mathrm{mM}$ of amine, where relevant. Dissolution of compounds was facilitated by stirring solutions. The electrolyte of the counter electrode cell compartment was charged with $3 \mathrm{M}$ tetraethylammonium acetate ( $\mathrm{NEt}_{4} \mathrm{OAc}$ ). Argon was sparged through the working solution via a PEEK tubing and a flow rate of $15 \mathrm{~mL} \mathrm{~min}{ }^{-1}$ was maintained throughout the experiment. Gaseous species were identified and quantified on an SRI-8610 gas chromatograph equipped with a thermal conductivity detector and flame ionization detector (multiple gas analyzer \#3, SRI Instruments).

\section{A.3 Product Quantification}

Product calibrations of gases were made using an analytical standard containing $0.5 \% \mathrm{H}_{2}, 0.5 \% \mathrm{O}_{2}, 0.5 \% \mathrm{CO}$, $0.5 \% \mathrm{CO}_{2}$ in nitrogen supplied by Sigma Aldrich (Supelco). The resultant peaks were integrated in the PeakSimple software and compared to experimental results for quantification. During flow experiments, 1 $\mathrm{mL}$ samples were taken from the headspace and measured accordingly. The column was maintained at 80 ${ }^{\circ} \mathrm{C}$ for the first $4 \mathrm{~min}$ and heated to $250{ }^{\circ} \mathrm{C}$ during the following $6 \mathrm{~min}$ to separate and analyze gases, followed by a 5 min cooldown period. Peaks were identified by comparison to the standards, integrated in the PeakSimple software and quantified accordingly.

For each flow experiment, the $\mathrm{H}_{2}$ peaks were integrated and then faradaic efficiency for each product gas was calculated according to,

$$
\begin{aligned}
& F E(A)=100\left[\frac{\frac{I_{\text {exp }} C F_{A}}{P_{a t m}+P_{\text {exp }}}}{\frac{(I)\left(\frac{60 s}{\min }\right)\left(\frac{1}{F}\right)\left(\frac{1}{2}\right)\left(\frac{22.4 L}{m o l}\right)}{F R}}\right] \\
& C F_{A}=\frac{\left(P_{\text {atm }}+P_{\text {calib }}\right)(0.005)}{I n t_{\text {calib }}}
\end{aligned}
$$


where $F E$ is faradaic efficiency, $A$ is the gaseous product being quantified $\left(\mathrm{H}_{2}\right) . \operatorname{Int} t_{\text {exp }}$ is the integration of the experimental peak measured for that gas, $C F_{A}$ is the calibration factor for gas $A$, calculated in Eq. (2). $P_{\text {atm }}$ is the atmospheric pressure in psi $(14.7 \mathrm{psi}), P_{\exp }$ is the experimental pressure of the gas flow into the GC in psi at the time of sample collection (typically $0.1 \mathrm{psi}$ ), I is the instantaneous current in amperes, $\mathrm{F}$ is the Faraday, $F R$ is the flow rate of $A r$ through the cell in $\mathrm{L} \mathrm{min}^{-1}$. CFA is calculated by Eq. (2), where $P_{\text {calib }}$ is the pressure of the flow for the calibration gas. This pressure is multiplied by the percentage concentration of $\mathrm{H}_{2}$ in the calibration gas (0.005) and divided by $I n t_{\text {calib, }}$ the integration of the calibration gas peak.

\section{B. Electrochemical Experiments}

\section{B.1 AcOH/Solvent Background CV}

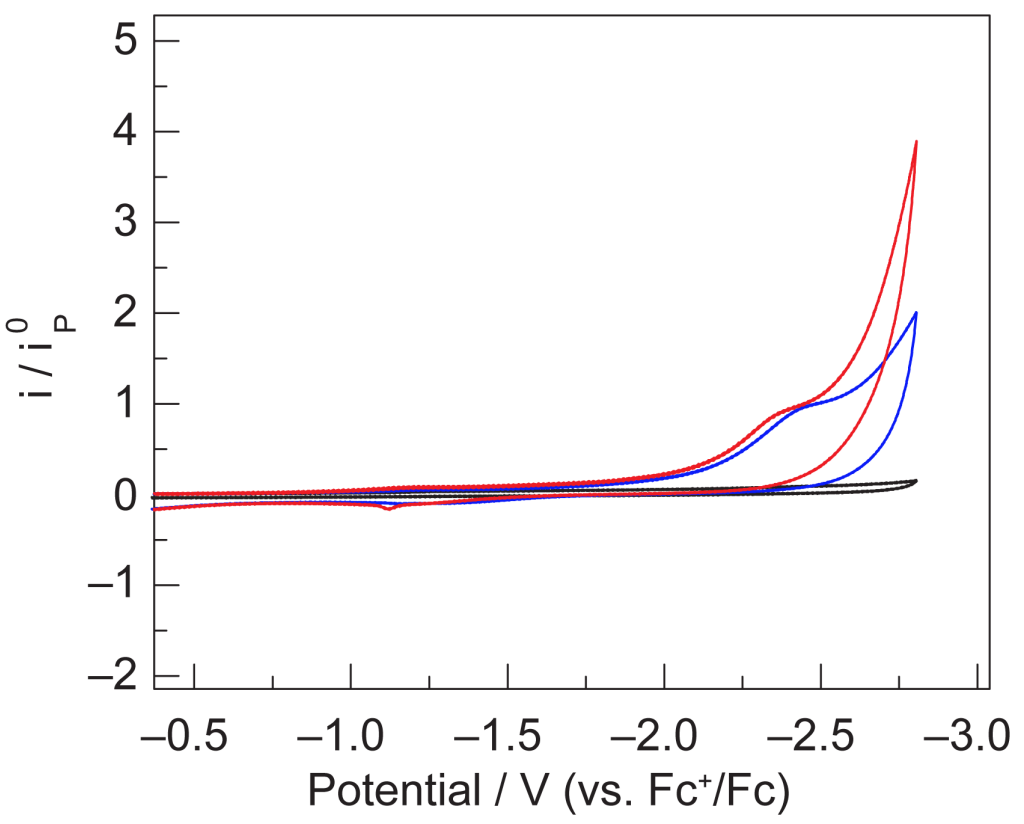

Figure S1. CVs of $0.1 \mathrm{M} \mathrm{NBu}_{4} \mathrm{PF}_{6}$ in DMF under argon with $0 \mathrm{mM}(-), 10 \mathrm{mM}(-)$ and $100 \mathrm{mM}(-) \mathrm{AcOH}$. Scans were taken at $0.1 \mathrm{~V} / \mathrm{s}$ using a $3 \mathrm{~mm}$ diameter glassy carbon electrode.

\section{B.2 Simulation of TPPFe CVs in the Presence of $+\mathrm{HNEt}_{3}$}

The experimental and simulated cyclic voltammograms (CVs) of TPPFe in the presence varying amounts of ${ }^{+} \mathrm{HNEt}_{3}$ are shown in Figure S2. 


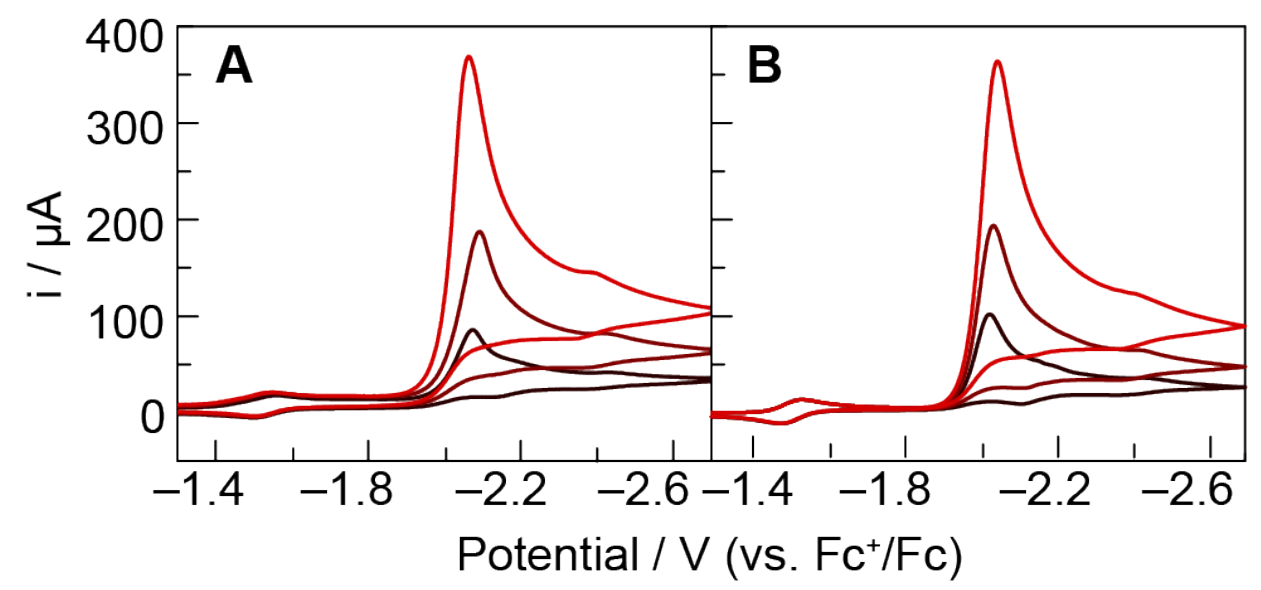

Figure S2. (A) CV of $1 \mathrm{mM}$ of TPPFe in the presence of 5 (black), 10 (crimson), 20 (red) $\mathrm{mM}^{+}{ }^{+} \mathrm{HNEt}_{3}$ under argon. Scans were taken at $0.1 \mathrm{~V} / \mathrm{s}$ in $0.1 \mathrm{M} \mathrm{NBu}_{4} \mathrm{PF}_{6}$ in $\mathrm{DMF}$ under argon using a $3 \mathrm{~mm}$ diameter glassy carbon electrode. (B) Simulations (see below for details).

Cyclic voltammograms are simulated using DigiElch software ${ }^{15}$ according to the reaction scheme given in Scheme S1. All diffusion coefficients for Fe species are $5 \times 10^{6} \mathrm{~cm}^{2} / \mathrm{s}$, diffusion coefficients for ${ }^{+} \mathrm{HNEt}_{3}$ and $\mathrm{NEt}_{3}$ are $8 \times 10^{6} \mathrm{~cm}^{2} / \mathrm{s}, \mathrm{S}=0.07 \mathrm{~cm}^{2}, T=293 \mathrm{~K}$. Electron transfer is fast $\left(k_{\mathrm{s}}=10^{4} \mathrm{~cm} \mathrm{~s}^{-1}\right)$ and chemical steps are irreversible $\left(K=10^{10}\right)$.

Scheme S1. Reaction scheme for the reduction of TPPFe(II) and its reactivity with ${ }^{+} \mathrm{HNEt}_{3}$ to form $\mathrm{H}_{2}$.

\begin{tabular}{ll}
\hline TPPFe(II) $+\mathrm{e}^{-} \rightleftarrows \mathrm{TPPFe}(\mathrm{I})$ & $E_{1}^{0}=-1.52 \mathrm{~V}\left(\mathrm{vs} \mathrm{Fc}^{+} / \mathrm{Fc}\right)$ \\
$\mathrm{TPPFe}(\mathrm{I})+\mathrm{e}^{-} \rightleftarrows \mathrm{TPPFe}(0)$ & $E_{2}^{0}=-2.15 \mathrm{~V}\left(\mathrm{vs} \mathrm{Fc}^{+} / \mathrm{Fc}\right)$ \\
$\mathrm{TPPFe}(\mathrm{II})+\mathrm{TPPFe}(0) \rightleftarrows 2 \mathrm{TPPFe}(\mathrm{I})$ & $k_{\mathrm{d}}=10^{10} \mathrm{M}^{-1} \mathrm{~s}^{-1}$ \\
$\mathrm{TPPFe}(0)+\mathrm{HNEt}_{3}^{+} \rightleftarrows \mathrm{TPPFe}(\mathrm{II}) \mathrm{H}+\mathrm{NEt}_{3}$ & $k_{1}=2 \cdot 10^{8} \mathrm{M}^{-1} \mathrm{~s}^{-1}$ \\
$\mathrm{TPPFe}(\mathrm{II}) \mathrm{H}+\mathrm{HNEt}_{3}^{+} \rightleftarrows \mathrm{TPPFe}(\mathrm{II})+\mathrm{NEt}_{3}+\mathrm{H}_{2}$ & $k_{2}=10^{5} \mathrm{M}^{-1} \mathrm{~s}^{-1}$ \\
$\mathrm{TPPFe}(\mathrm{II}) \mathrm{H}+\mathrm{e}^{-} \rightleftarrows \mathrm{TPPFe}(\mathrm{I}) \mathrm{H}$ & $E_{3}^{0}=-2.43 \mathrm{~V}\left(\mathrm{vs} \mathrm{Fc}^{+} / \mathrm{Fc}\right)$
\end{tabular}




\section{B.3 LSV with Water Titration}

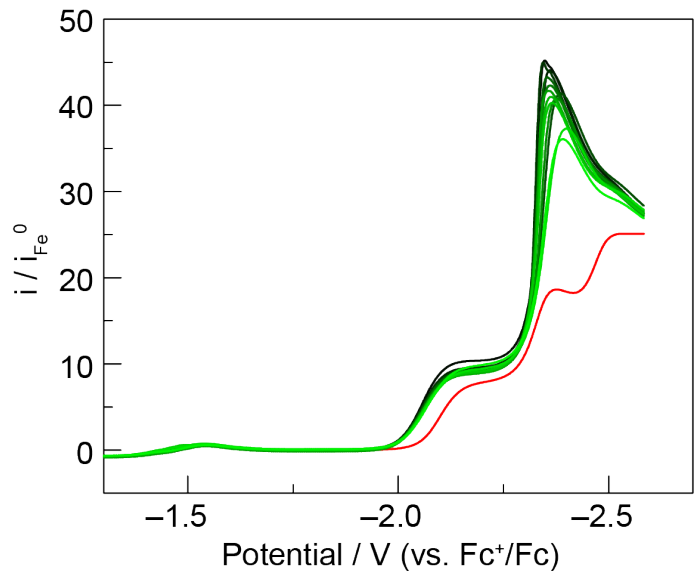

Figure S3. Linear voltammetry of TPPFe $(1 \mathrm{mM})$ with $40 \mathrm{mM} \mathrm{AcOH}(-)$ and $10 \mathrm{mM}$ of N(i-Pr 2$)$ Et with water titrated in from $0.25 \mathrm{mM}(-)$ up to $40 \mathrm{mM}(-)$. Scans were taken at $0.1 \mathrm{~V} / \mathrm{s}$ in $0.1 \mathrm{M} \mathrm{NBu}_{4} \mathrm{PF}_{6}$ in $\mathrm{DMF}$ under argon using a glassy carbon electrode.

\section{B.4 Determination of Association of Base to TPPFe}

As can be seen on Figure S4, TPPFe(I)/TPPFe(0) wave is not affected by the presence of Quinuclidine (Quin), DABCO, N-EtPip, NEt $\mathrm{N}_{3}$ and $\mathrm{N}\left(i-\mathrm{Pr}_{2}\right)$ Et. Hence, we can assume that the binding constant with both TPPFe(0) and TPPFe(I) is small. Indeed, the apparent standard potential is,

$E_{2, a p}^{0}=E_{2}^{0}+\frac{\mathrm{R} T}{\mathrm{~F}} \ln \left(\frac{1+K_{0}[\text { base }]}{1+K_{I}[\text { base }]}\right)$

where $K_{I}$ and $K_{0}$ are the binding constants of the base with TPPFe(I) and TPPFe(0) respectively. Typically, $K_{0}$ and $K_{I} \ll<1 \mathrm{M}^{-1}$.

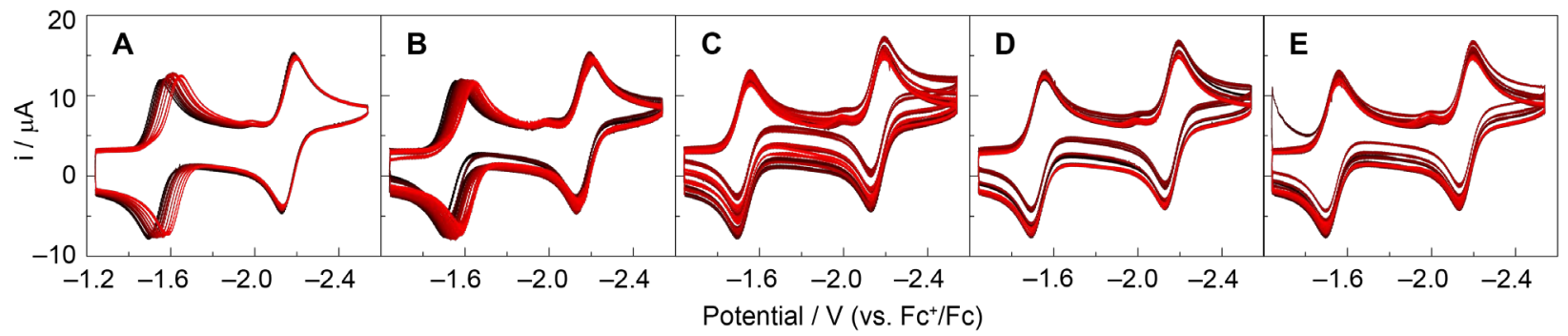

Figure S4. CVs of $1 \mathrm{mM}$ of TPPFe in presence of $0(-), 0.25,0.5,0.75,1,1.5,2,2.5,5,10,20,40 \mathrm{mM}(-)$ of $\mathbf{A}$ Quin, $\mathbf{B}$ DABCO, C N-EtPip, $\mathbf{D} ~ N E t_{3}, \mathbf{E ~ N}\left(i-\mathrm{Pr}_{2}\right)$ Et. Scans were taken at $0.1 \mathrm{~V} / \mathrm{s}$ under argon in DMF +0.1 $\mathrm{M} n-\mathrm{Bu}_{4} \mathrm{NPF}_{6}$ using a glassy carbon electrode. 
As can be seen on Figure S4, the TPPFe(II)/TPPFe(I) wave is affected by the presence of Quin and DABCO and not by addition of N-EtPip, $\mathrm{NEt}_{3}$ and $\mathrm{N}\left(i-\mathrm{Pr}_{2}\right) \mathrm{Et}$. In the case of Quin and $\mathrm{DABCO}$, assuming a 1:1 association of the base with TPPFe(II), the apparent standard potential (obtained from the half-sum of the reduction and oxidation peak potentials) is fitted by

$E_{1, a p}^{0}=E_{1}^{0}-\frac{R T}{F} \ln \left(1+K_{I I}[\mathrm{~B}]\right)$

where $K_{I I}$ is the binding constants of the base with TPPFe(II) (Figure S5), leading to constant $K_{I I}=14000$ $\mathrm{M}^{-1}$ in both cases.
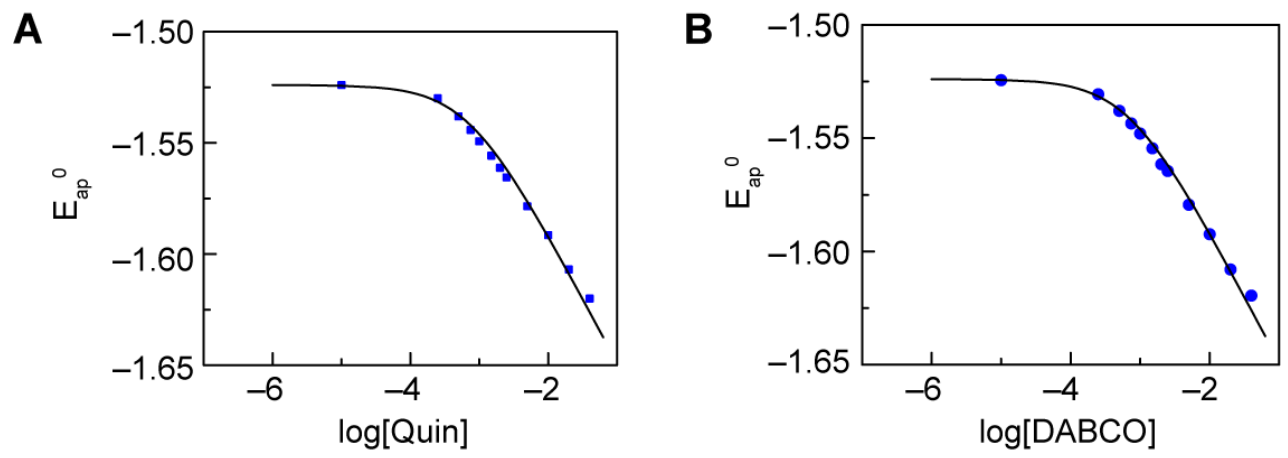

Figure S5. Plot of the apparent standard potential $(\bullet)$ of the TPPFe(II/I) redox wave as a function of the amount of added amine (mM) with 1:1 binding fit (-) for A Quin and B DABCO.

\section{B.5 Simulations of LSV to Obtain $k_{1 \text {,ap }}$ and $k_{2 \text {,ap }}$}

Cyclic voltammograms are simulated using DigiElch software ${ }^{1 \mathrm{~S}}$ according to the reaction scheme given in Scheme S2. All diffusion coefficients for Fe species are $5 \times 10^{6} \mathrm{~cm}^{2} / \mathrm{s}$, diffusion coefficients for AcOH and $\mathrm{AcO}^{-}$are $8 \times 10^{6} \mathrm{~cm}^{2} / \mathrm{s}, \mathrm{S}=0.07 \mathrm{~cm}^{2}, T=293 \mathrm{~K}$. Electron transfer is fast $\left(\mathrm{ks}_{\mathrm{s}}=10^{4} \mathrm{~cm} \mathrm{~s}^{-1}\right)$ and chemical steps are irreversible $\left(K=10^{10}\right)$.

Scheme S2. Reaction scheme for the reduction of TPPFe(II) and its reactivity with $\mathrm{AcOH}$ to form $\mathrm{H}_{2}$.

\begin{tabular}{ll}
\hline TPPFe(II) $+\mathrm{e}^{-} \rightleftarrows \mathrm{TPPFe}(\mathrm{I})$ & $E_{1}^{0}=-1.52 \mathrm{~V}\left(\mathrm{vs} \mathrm{Fc}^{+} / \mathrm{Fc}\right)$ \\
$\mathrm{TPPFe}(\mathrm{I})+\mathrm{e}^{-} \rightleftarrows \mathrm{TPPFe}(0)$ & $E_{2}^{0}=-2.15 \mathrm{~V}\left(\mathrm{vs} \mathrm{Fc}^{+} / \mathrm{Fc}\right)$ \\
$\mathrm{TPPFe}(\mathrm{II})+\mathrm{TPPFe}(0) \rightleftarrows 2 \mathrm{TPPFe}(\mathrm{I})$ & $k_{\mathrm{d}}=10^{10} \mathrm{M}^{-1} \mathrm{~s}^{-1}$ \\
$\mathrm{TPPFe}(0)+\mathrm{AcOH} \rightleftarrows \mathrm{TPPFe}(\mathrm{II}) \mathrm{H}+\mathrm{AcO}^{-}$ & $k_{1, \mathrm{ap}}$ \\
$\mathrm{TPPFe}(\mathrm{II}) \mathrm{H}+\mathrm{AcOH} \rightleftarrows \mathrm{TPPFe}(\mathrm{II})+\mathrm{AcO}^{-}+\mathrm{H}_{2}$ & $k_{2, \mathrm{ap}}$ \\
\hline
\end{tabular}


Rate constants $k_{1, \text { ap }}$ and $k_{2, \text { ap }}$ are determined from simulations by fitting both position and current intensity. However, to obtain guess values to start the fitting process we used analytical expressions derived for both EECC and ECCE' mechanisms ${ }^{25}$ in the case of pure kinetics conditions and no substrate consumption as well as assuming irreversible chemical steps.

In the EECC case:

$\frac{i_{p l}}{i_{p}^{0}}=\frac{1}{0.446 \sqrt{\frac{F v}{R T}}}\left[\frac{2 \sqrt{k_{1, a p}[\mathrm{AcOH}]_{0}}}{1+\frac{1}{\left(1+\sqrt{\left.\frac{k_{2, a p}}{k_{1, a p}}\right) \sqrt{\frac{k_{2, a p}}{k_{1, a p}}}}\right.}}\right]$

and

$E_{1 / 2}=E_{2}^{0}+\frac{R T}{F} \ln \left(1+\frac{1}{\left(1+\sqrt{\frac{k_{2 a p}}{k_{1 a p}}}\right) \sqrt{\frac{k_{2 a p}}{k_{1 a p}}}}\right)$

In the ECCE' case: considering $k_{1, \text { ap }} \gg>k_{2, a p}$

$\frac{i_{p l}}{i_{p}^{0}}=\frac{1}{0.446 \sqrt{\frac{F v}{R T}}}\left[\frac{2 \sqrt{k_{2, a p}[\mathrm{AcOH}]_{0}}}{1+\sqrt{\frac{k_{2, a p}}{k_{1, a p}}}}\right]$

and

$$
E_{1 / 2}=E^{0}-\frac{R T}{F} \ln \left(\frac{\left(2+\sqrt{\frac{k_{2 a p}}{k_{1 a p}}}\right) \sqrt{\frac{k_{2 a p}}{k_{1 a p}}}}{\left(1+\sqrt{\frac{k_{2 a p}}{k_{1 a p}}}\right)^{2}}\right)
$$

Rate constants obtained from these equations are shown in Figure S6 together with the rate constants obtained from full simulations according to Scheme S2. As expected, it is seen that for $k_{1, \text { ap }}$ the ECCE' values match the simulated values at low base concentration (i.e. small catalysis) whereas it matches the EECC values at larger base concentration (i.e. large catalysis). The $k_{2, a p}$ values from ECCE and ECCE' underestimate the simulated values because (i) it does not consider the effect of consumption of $\mathrm{AcOH}$ (not fully negligible at $40 \mathrm{mM}$ although the CV looks plateau-shaped) and (ii) at small added base concentrations where catalysis is not very high, the effect of the catalyst wave (which is neglected in the derivation of the equation) is not negligible. 

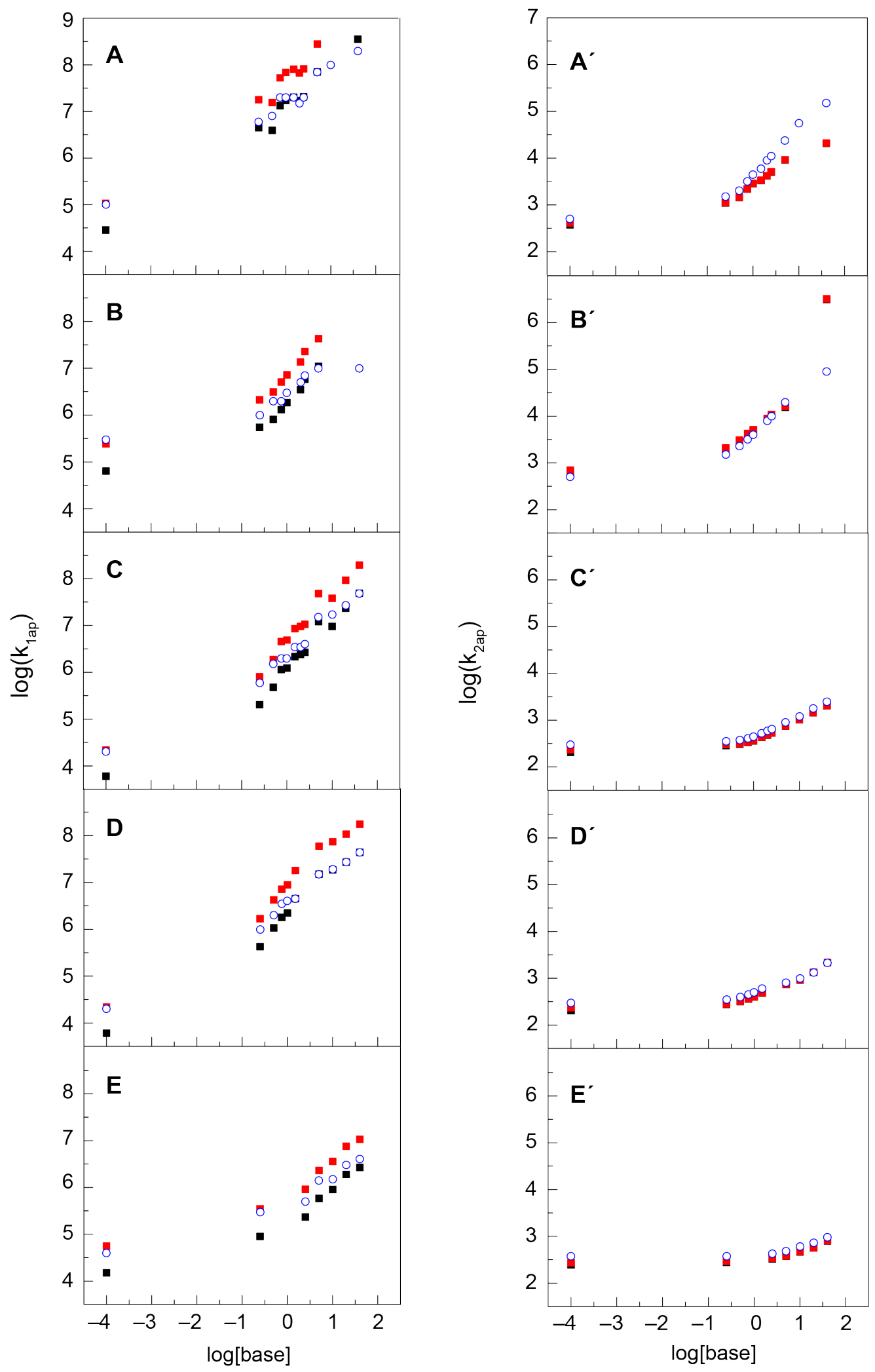

Figure S6. Apparent rate constants $k_{1, \text { ap }}$ (left) and $k_{2, \text { ap }}$ (right) obtained from analytical expressions: EECC (-),

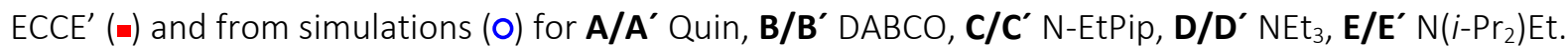



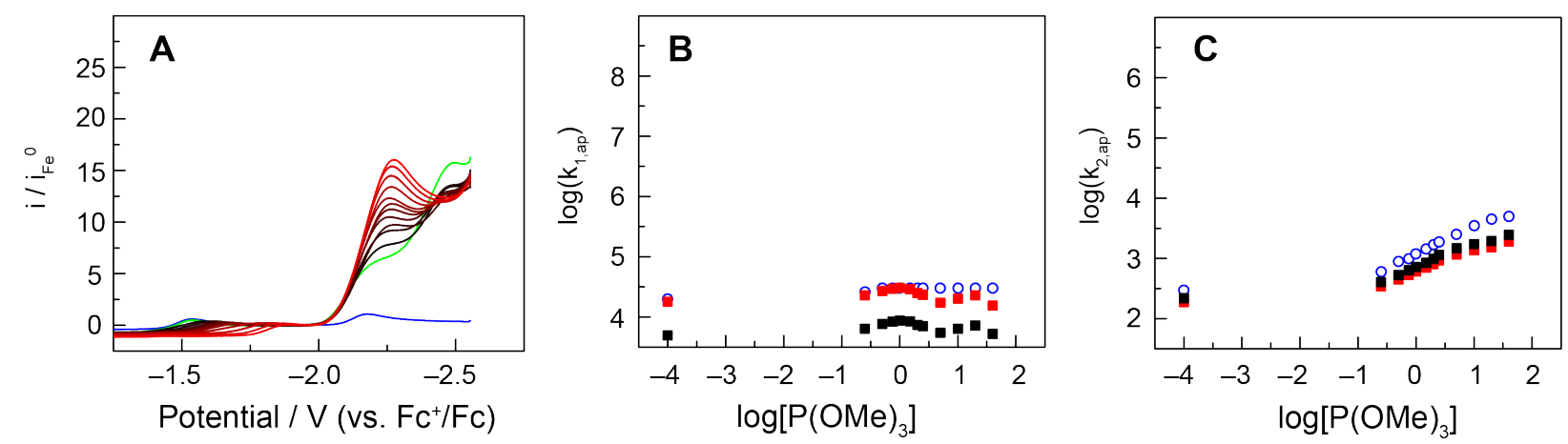

Figure S7. A Linear scan voltammograms of TPPFe $(1 \mathrm{mM})(-)$ in the presence of $40 \mathrm{mM} \mathrm{AcOH}(-)$ with $\mathrm{P}(\mathrm{OMe})_{3}$ added in the range of $0.25 \mathrm{mM}(-)$ up to $40 \mathrm{mM}(-)$. Scans were taken at $0.1 \mathrm{~V} / \mathrm{s}$ in $0.1 \mathrm{M} \mathrm{NBu}_{4} \mathrm{PF}_{6}$ in DMF under argon using a $3 \mathrm{~mm}$ diameter glassy carbon electrode. Apparent rate constants $\mathbf{B} k_{1, \text { ap }}$ (left) and $\mathbf{C} k_{2, \text { ap }}$ (right) obtained from analytical expressions: EECC (-), ECCE' (-) and from simulations (o) for $\mathrm{P}(\mathrm{OMe})_{3}$ additions to working solutions of $1 \mathrm{mM}$ TPPFe and $40 \mathrm{mM} \mathrm{AcOH}$.

\section{B.6 Simulations of LSV to Obtain $\boldsymbol{k}_{\mathbf{1}, \boldsymbol{B} \boldsymbol{H}^{+}}$and $\boldsymbol{k}_{2, \boldsymbol{B} \boldsymbol{H}^{+}}$}

Cyclic voltammograms are simulated using DigiElch software ${ }^{15}$ according to the reaction sequence given in Scheme S3. All diffusion coefficients for Fe species are $5 \times 10^{6} \mathrm{~cm}^{2} / \mathrm{s}$, diffusion coefficients for AcOH and $\mathrm{AcO}^{-}$are $8 \times 10^{6} \mathrm{~cm}^{2} / \mathrm{s}, \mathrm{S}=0.07 \mathrm{~cm}^{2}, T=293 \mathrm{~K}$. Electron transfer is fast $\left(k_{\mathrm{s}}=10^{4} \mathrm{~cm} \mathrm{~s}^{-1}\right)$ and chemical steps (except $\mathrm{AcOH} / \mathrm{B}$ proton exchange) are irreversible. Rate constants are given in Table S1 and simulations shown in Figure S9.

Scheme S3. Reaction scheme for the reduction of protons to $\mathrm{H}_{2}$ by TPPFe using protonated amine as a proton source.

\begin{tabular}{ll}
\hline $\mathrm{TPPFe}(\mathrm{II})+\mathrm{e}^{-} \rightleftarrows \mathrm{TPPFe}(\mathrm{I})$ & $E_{1}^{0}=-1.52 \mathrm{~V}\left(\mathrm{vs} \mathrm{Fc}^{+} / \mathrm{Fc}\right)$ \\
$\mathrm{TPPFe}(\mathrm{I})+\mathrm{e}^{-} \rightleftarrows \mathrm{TPPFe}(0)$ & $E_{2}^{0}=-2.154 \mathrm{~V}\left(\mathrm{vs} \mathrm{Fc}^{+} / \mathrm{Fc}\right)$ \\
$\mathrm{TPPFe}(\mathrm{II})+\mathrm{TPPFe}(0) \rightleftarrows 2 \mathrm{TPPFe}(\mathrm{I})$ & $k_{\mathrm{d}}=10^{10} \mathrm{M}^{-1} \mathrm{~s}^{-1}$ \\
$\mathrm{AcOH}+\mathrm{B} \rightleftarrows \mathrm{AcO}^{-}+\mathrm{BH}^{+}$ & $K_{\mathrm{A}, \mathrm{B}}=10^{\mathrm{pK}_{\mathrm{a}, \mathrm{B}}-13.2}, \mathrm{k}_{-\mathrm{A}, \mathrm{B}}=10^{10} \mathrm{M}^{-1} \mathrm{~s}^{-1}$ \\
$\mathrm{TPPFe}(0)+\mathrm{BH}^{+} \rightleftarrows \mathrm{TPPFe}(\mathrm{II}) \mathrm{H}+\mathrm{B}$ & $k_{1, \mathrm{BH}^{+}}\left(\mathrm{M}^{-1} \mathrm{~s}^{-1}\right)$ \\
$\mathrm{TPPFe}(\mathrm{II}) \mathrm{H}+\mathrm{BH}^{+} \rightleftarrows \mathrm{TPPFe}(\mathrm{II})+\mathrm{B}+\mathrm{H}_{2}$ & $k_{2, \mathrm{BH}^{+}}\left(\mathrm{M}^{-1} \mathrm{~s}^{-1}\right)$ \\
\hline
\end{tabular}


Table S1. Tabulated values for the conjugate acid $\mathrm{p} K_{a, B}$ and rate constants associated with each step of the catalytic reaction with various amines added to solution when the conjugate acid of the added amine is driving catalysis.

\begin{tabular}{|c|c|c|c|}
\hline Base (B) & $\mathrm{p} K_{a, B}{ }^{a}$ & $k_{1, \mathrm{BH}+}\left(\mathrm{M}^{-1} \mathrm{~s}^{-1}\right)$ & $K_{2, \mathrm{BH}}\left(\mathrm{M}^{-1} \mathrm{~s}^{-1}\right)$ \\
\hline Quin & 10.16 & $6.6 \cdot 10^{7 c}$ & $3 \cdot 10^{4} \mathrm{c}$ \\
\hline DABCO & 9.25 & $1.9 \cdot 10^{8 c}$ & $10^{5 c}$ \\
\hline N-EtPip & $11.3^{d}$ & $1.8 \cdot 10^{7} \mathrm{c}$ & $9 \cdot 10^{3 c}$ \\
\hline $\mathrm{NEt}_{3}$ & 9.2 & $2 \cdot 10^{8 b}$ & $10^{5 b}$ \\
\hline $\mathrm{N}\left(i-\mathrm{Pr}_{2}\right) \mathrm{Et}$ & 8.8 & $3.2 \cdot 10^{8 c}$ & $1.6 \cdot 10^{5} c$ \\
\hline
\end{tabular}

${ }^{a}$ From correlation with values in DMSO. ${ }^{b}$ From simulation of experiments with ${ }^{+} \mathrm{HNEt}_{3}$, see Figure S3.

${ }^{c}$ Estimated assuming a correlation with $\mathrm{p} K_{a, B}$ values with $\partial \log k_{1, \mathrm{BH}}+\partial \mathrm{p} K_{\mathrm{a}}=-0.5 .{ }^{d}$ Assumed to be identical to piperidine. 


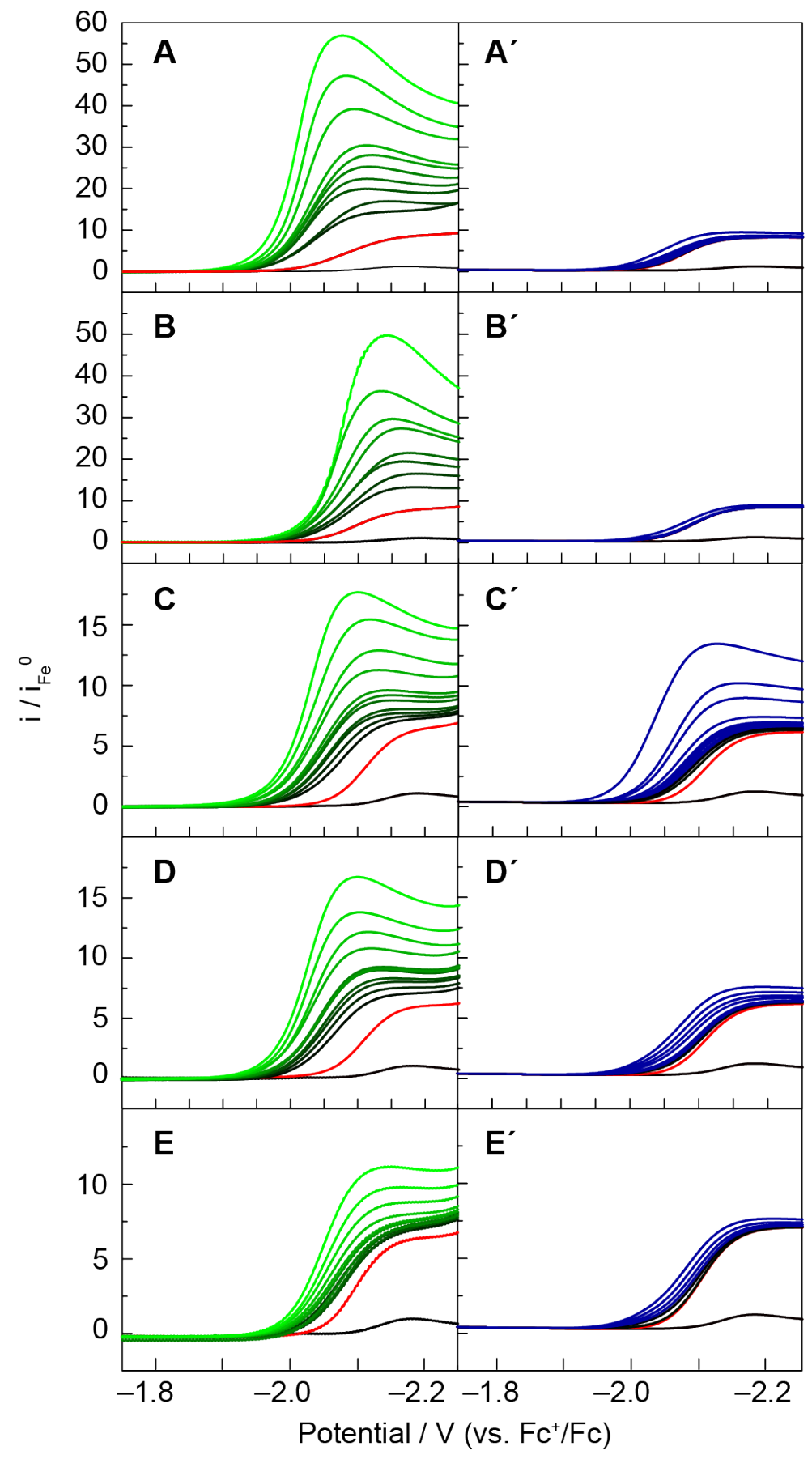

Figure S8. Linear scan voltammograms of $1 \mathrm{mM}$ TPPFe (-) with $40 \mathrm{mM}$ of AcOH (-) plus $0.25 \mathrm{mM}(-)$ up to $40 \mathrm{mM}(-)$ of added amine from experiments (A,B,C,D,E). Simulated linear scan voltammograms derived from acid-base hypothesis of TPPFe (-) with $40 \mathrm{mM}$ of AcOH (-) plus $0.25 \mathrm{mM}(-)$ up to $40 \mathrm{mM}(-)$ of

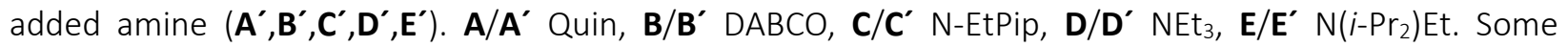
concentration levels are omitted for clarity of simulation and experimental data. Scans were taken at 0.1 $\mathrm{V} / \mathrm{s}$ in $0.1 \mathrm{M} n-\mathrm{NBu}_{4} \mathrm{PF}_{6}$ in DMF under argon using a glassy carbon electrode. 

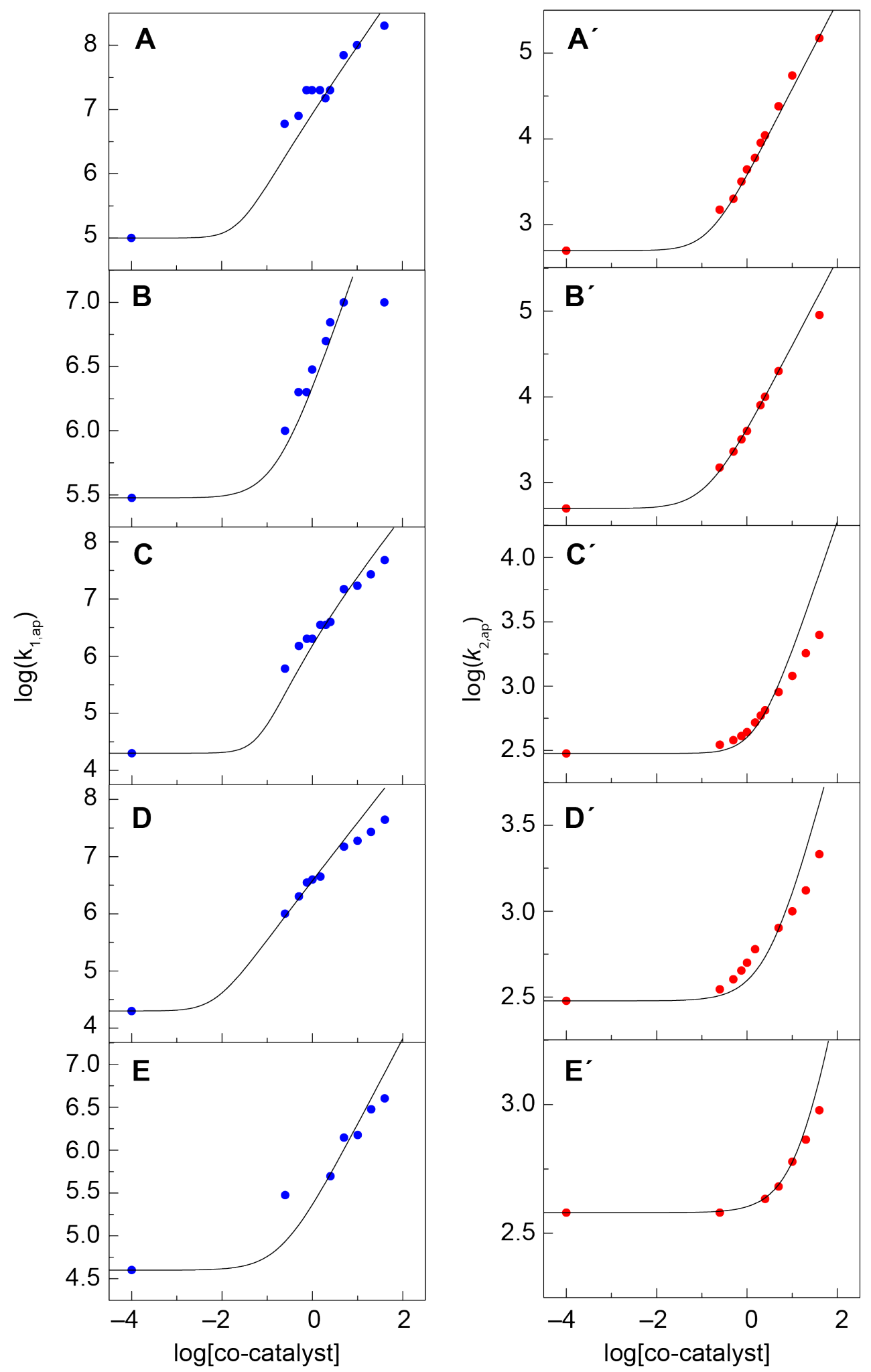

Figure S9. Adjustment of rate constants $k_{1, \text { ap }}(\cdot)$ and $k_{2, \text { ap }}(\cdot)$ according to Eq. 4 in the main text for $\mathbf{A} / \mathbf{A}^{\prime}$

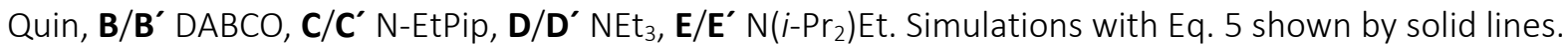




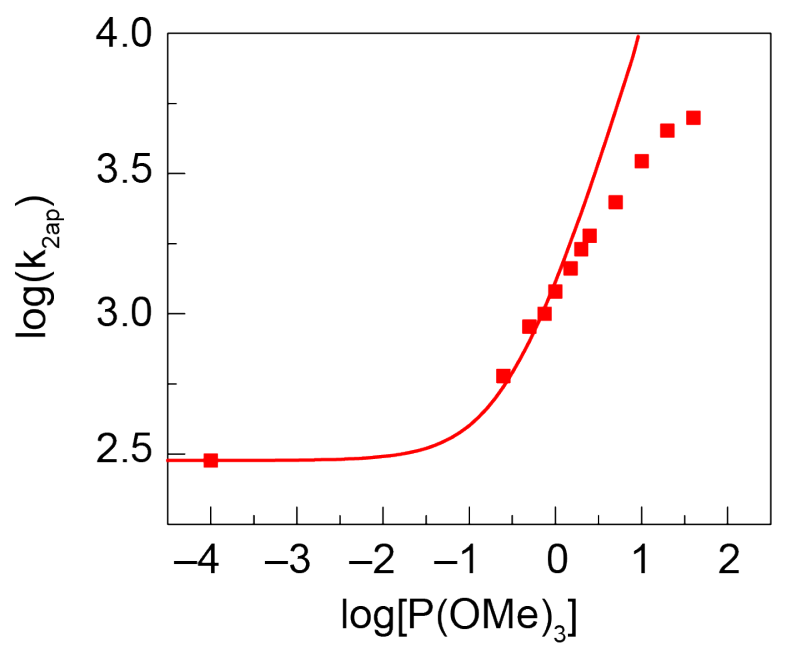

Figure S10. Apparent rate constants as function of added $\mathrm{P}(\mathrm{OMe})_{3}(\mathrm{mM})$ (red dots: $k_{2, \text { ap }}$ data; red line: simulation with Eq. 7 in the main text. 


\section{NMR Titration Experiments}

NMR experiments probing the heteroconjugation of $\mathrm{AcOH}$ with each amine studied in the text were performed by adding $250 \mu \mathrm{L}$ of an $80 \mathrm{mM}$ stock solution of $\mathrm{AcOH}$ with $125 \mu \mathrm{L}$ of an $80 \mathrm{mM}$ stock solution of each amine and diluting with an additional $125 \mu \mathrm{L}$ of DMF- $\mathrm{d}_{7}$ for a total of $0.5 \mathrm{~mL}$ experiments.

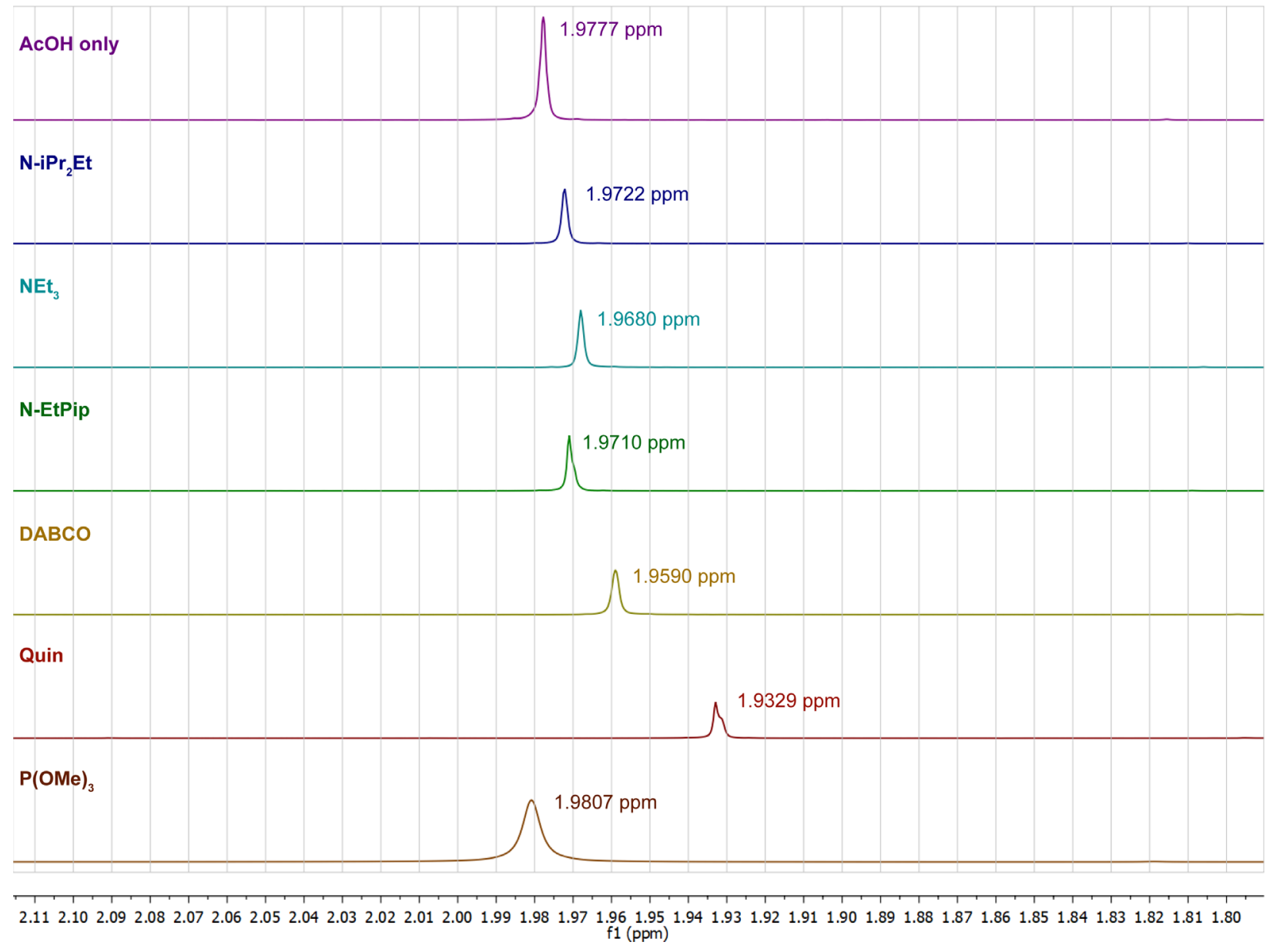

Figure S11. ${ }^{1} \mathrm{H}$ NMR spectra of AcOH methyl peak with no amine (-), $20 \mathrm{mM} \mathrm{N}\left(i-\mathrm{Pr}_{2}\right)$ Et $(-), 20 \mathrm{mM} \mathrm{NEt}_{3}(-$ ), $20 \mathrm{mM} \mathrm{N}$-EtPip (-), $20 \mathrm{mM}$ DABCO (-), $20 \mathrm{mM}$ Quin (-) and $20 \mathrm{mM} \mathrm{P(OMe})_{3}(-)$. 


\section{IR Experiment}

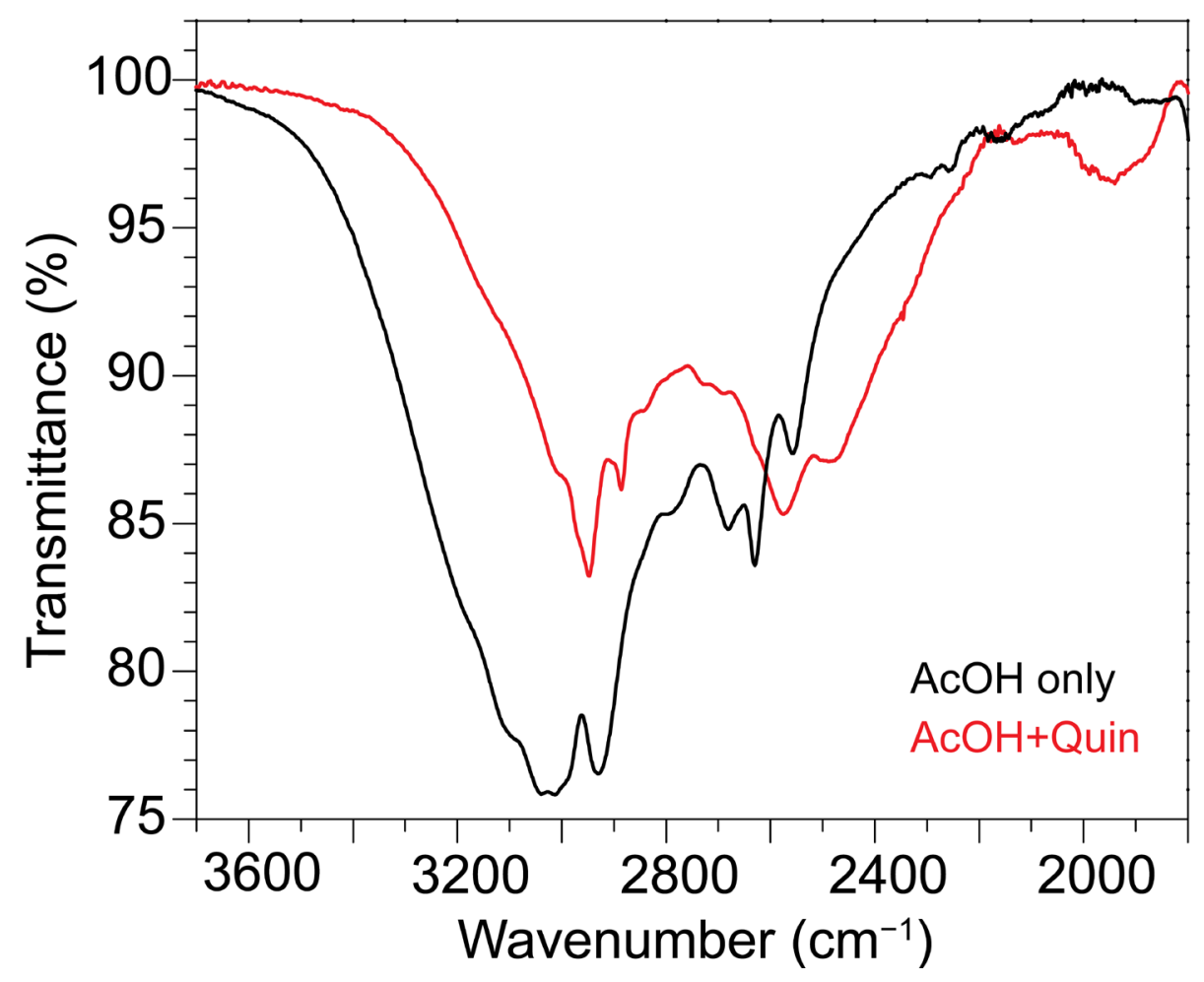

Figure S12. IR spectra of neat $\mathrm{AcOH}(-)$ and $\mathrm{AcOH}$ :Quin (-) in a 4:1 molar ratio. 


\section{E. References}

1S. Rudolph, M. Digital Simulations on Unequally Spaced Grids.: Part 2. Using the Box Method by Discretisation on a Transformed Equally Spaced Grid. J. Electroanal. Chem. 2003, 543, 23-39.

2S. Costentin, C., Savéant, J.-M. Homogeneous Catalysis of Electrochemical Reactions: The Steady-State and Nonsteady-State Statuses of Intermediates. ACS Catal. 2018, 8, 5286-5297. 